\title{
A Formaldehyde Exposure Assessment Tool for Occupants of FEMA Temporary Housing Units
}

\author{
Srinandini Parthasarathy, Michael Spears, Randy L. Maddalena, \\ Marion L Russell, Michael G. Apte \\ Environmental Energy Technologies Division \\ Indoor Environment Department \\ Lawrence Berkeley National Laboratory \\ Berkeley, CA 94720
}

October 2010

This work was supported by interagency agreement 08FED894632 by the National Center for Environmental Health (NCEH) of the Centers for Disease Control and Prevention (CDC) and the Assistant Secretary for Energy Efficiency and Renewable Energy, Office of Building Technology, State, and Community Programs of the U.S. Department of Energy (DOE) under Contract DE-AC02-05CH11231. 


\begin{abstract}
The report outlines the methodology used to develop a web-based tool to assess the formaldehyde exposure of the occupants of Federal Emergency Management Administration (FEMA) temporary housing units (THUs) after Hurricanes Katrina and Rita in 2005. Linear regression models were built using available data to retrospectively estimate the indoor temperature and relative humidity, formaldehyde emission factors and concentration, and hence the formaldehyde exposures. The interactive web-tool allows the user to define the inputs to the model to evaluate formaldehyde exposures for different scenarios.
\end{abstract}




\section{TABLE OF CONTENTS}

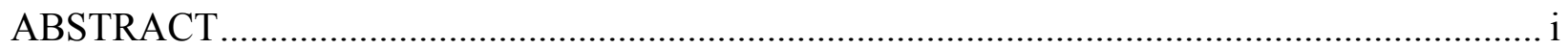

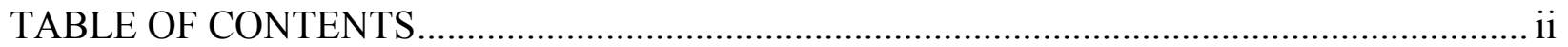

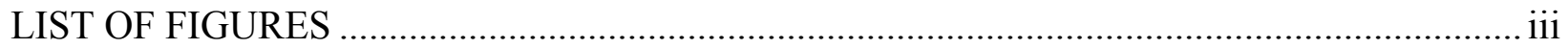

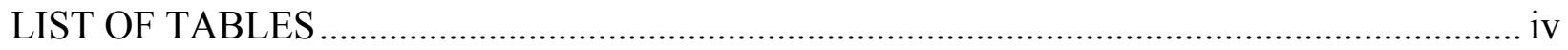

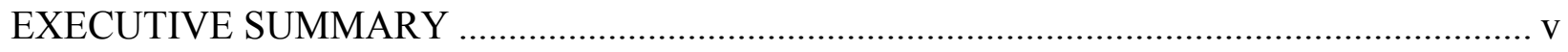

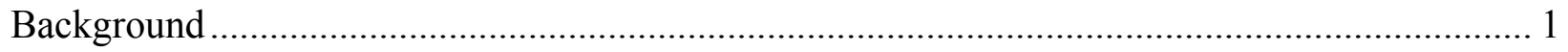

Materials emitting formaldehyde ………………………................................................ 1

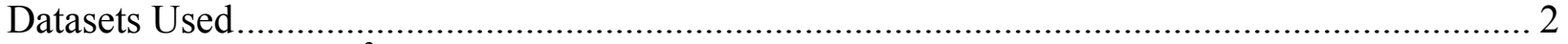

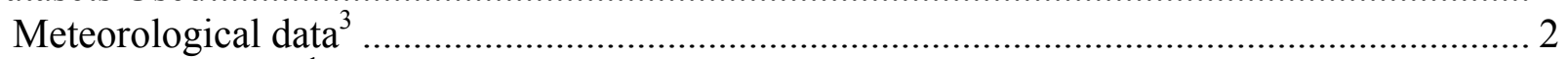

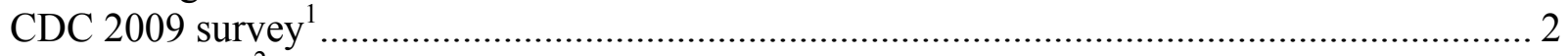

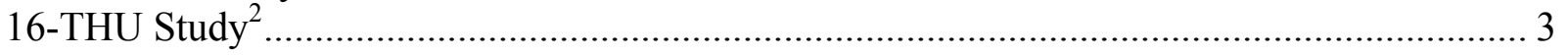

EXPOSURE ASSESSMENT METHODOLOGY …………………….................................... 3

1) Predicting Indoor Temperature and Relative Humidity in all THU types ................................ 4

Estimating indoor temperature in all THU types: .................................................................. 4

Estimating indoor relative humidity in all THU types:....................................................... 4

2) Estimating Formaldehyde concentration in the Park Model, Mobile Home and Other THUs

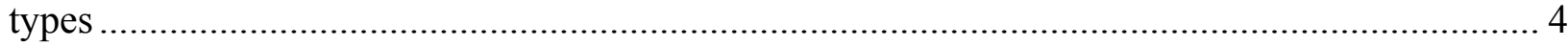

3) Estimate of Formaldehyde Emission Factors in Travel Trailer THUs ..................................... 5

Estimating air change rate for travel trailer types: ................................................................... 5

Variability across travel trailer manufacturer types: ………………………………………........ 6

4) Estimate of Steady-State Formaldehyde Concentration in the THUs ......................................... 6

5) Cumulative Formaldehyde Exposure ……………….......................................................... 6

FORMALDEHYDE EXPOSURE ASSESSMENT WEB TOOL .............................................. 7

Travel trailer model validation using CDC survey dataset.......................................................... 8

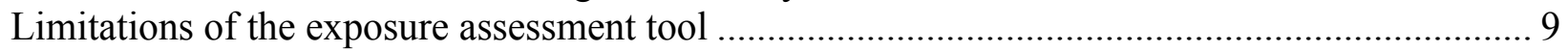

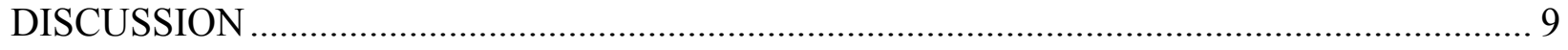

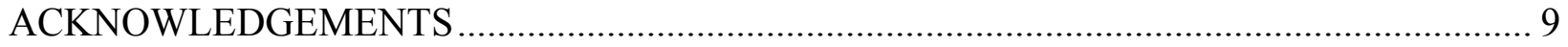

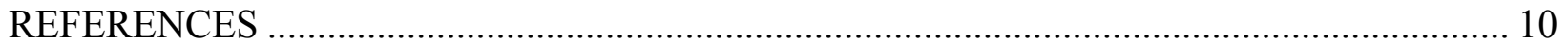

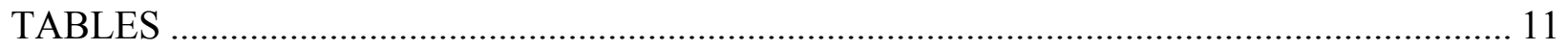

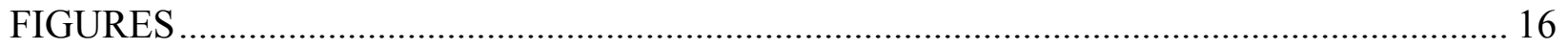

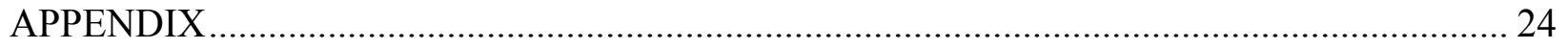

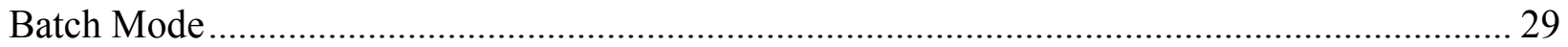




\section{LIST OF FIGURES}

Figure 1 - Indoor Temperature Prediction

Figure 2 - Indoor Relative Humidity Prediction

Figure 3 - Park Model, Mobile Home, Other THU Formaldehyde Emission Factor Calculation

Figure 4 - Travel Trailer Formaldehyde Emission Factor Prediction

Figure 5 - Steady-state Formaldehyde Concentration in THUs

Figure 6 - Error Minimization Methodology to Estimate Air Change Rates in Travel Trailer THUs

Figure 7 - Exposure Assessment in THUs

Figure 8 - Model Validation Plot of Measured Concentration $\left(\mathrm{C}_{\text {meas }}\right)$ against Predicted Concentration $\left(\mathrm{C}_{\text {pred }}\right)$ 


\section{LIST OF TABLES}

Table 1 - THU Location. Statistics from the CDC Survey.

Table 2 - THU year of manufacture. Statistics from the CDC Survey

Table 3 - THU Type. Statistics from the CDC Survey

Table 4 - Window usage. Statistics from the CDC Survey

Table 5 - Heating usage. Statistics from the CDC Survey

Table 6 - Air conditioning usage. Statistics from the CDC Survey

Table 7 - Fan usage. Statistics from the CDC Survey

Table 8 - Temperature statistics. Statistics from the CDC Survey

Table 9 - Relative humidity statistics. Statistics from the CDC Survey

Table 10 - Steady state concentrations from 16-THU Study in the AM (midnight-noon) and PM (noon-midnight ) and floor area normalized emission factors of formaldehyde

Table 11 - Indoor Temperature Prediction Model from 16-THU Study

Table 12 - Indoor Relative Humidity Prediction Model from 16-THU Study

Table 13 - Formaldehyde Concentration in Mobile Homes, Park Models and Other THUs Prediction Model

Table 14 - Formaldehyde Emission Factor in Travel Trailers Prediction Model

Table 15 - Air Change Rate Values Used

Table 16 - Trailer dimensions 


\section{EXECUTIVE SUMMARY}

The objective of this study was to estimate the formaldehyde exposure experienced by occupants of the Federal Emergency Management Administration (FEMA) temporary housing units (THUs). An empirical web-based formaldehyde exposure assessment tool was developed as described in this report.

The tool is based on a set of regression models to estimate the formaldehyde emission factors in THUs. The emission factors are subsequently used to estimate exposure concentrations, which are combined with activity pattern information provided by the user to estimate the formaldehyde exposure experience by THU occupants. The regression models were derived using data from the following studies:

CDC 2009 survey $^{1}-$

Between December 2007 and April 2009, the Centers for Disease Control and Prevention (CDC) carried out continuous one hour formaldehyde sampling in various THUs. The indoor temperature and relative humidity during sampling were measured. The CDC also administered a survey to the THU occupants to determine whether any routine daily activity contributed to formaldehyde levels in the THUs. The sampling and survey were carried out in THUs of the travel trailer, park model, mobile home and other types. The information from this survey was documented and shared with LBNL. The survey included THUs that were located primarily in Louisiana and Mississippi.

16-THU study ${ }^{2}$

In May 2009, Parthasarathy et al. ${ }^{2}$ measured concentrations and estimated emission rates of volatile organic compounds (VOCs) in 16 unoccupied THUs located in Purvis Mississippi, USA. Emission factors were reported for 36 VOCs including formaldehyde. Indoor temperature and relative humidity $(\mathrm{RH})$ were also measured in all the trailers during sampling. Indoor temperatures were varied (increased or decreased) in a subset of THUs s using the heating and air conditioning systems. Indoor temperatures during sampling ranged from $14^{\circ} \mathrm{C}$ to $33^{\circ} \mathrm{C}$, and relative humidity $(\mathrm{RH})$ varied between $35 \%$ to $74 \%$. Ventilation rates were also increased in some trailers using exhaust fans and vents during some of the sampling events. Ventilation rates varied from 0.14 to $4.3 \mathrm{~h}^{-1}$.

Weather data ${ }^{3}$

Hourly outdoor temperature and relative humidity at weather stations near the locations of interest were obtained from National Oceanic and Atmospheric Administration (NOAA).

The following regression models were constructed:

1) Indoor temperature in the THUs - A linear regression model was built with indoor temperature as the dependent variable, outdoor temperature from NOAAs weather data ${ }^{3}$ as a continuous independent variable, and air conditioning and heating usage from CDC survey ${ }^{1}$ as categorical independent variables.

2) Indoor relative humidity in the THUs - A linear regression model was built with indoor relative humidity as the dependent variable, outdoor relative humidity from NOAAs weather data ${ }^{3}$ as a continuous independent variable, air conditioning and heating usage from CDC survey ${ }^{1}$ as categorical independent variables. 
3) Formaldehyde emission factor in the travel trailer type THUs ${ }^{2}$ - A linear regression model was derived with formaldehyde emission factor as the dependent variable, using continuous independent variables including the log of the predicted percent indoor relative humidity, the inverse of predicted indoor temperature (in $\mathrm{K}^{-1}$ ), and the inverse log of the user supplied air change rate $(\mathrm{ACH})$ and categorical independent variables including trailer manufacturer. A simple mass balance and data on occupancy patterns were then used to estimate the indoor concentrations and exposures.

4) Formaldehyde concentration in the park models, mobile homes and other type THUs ${ }^{1}-\mathrm{A}$ linear regression model was derived with the formaldehyde emission factor as the dependent variable, with continuous independent variables including the log of predicted percent indoor relative humidity and inverse of predicted indoor temperature (in $\mathrm{K}^{-1}$ ). Categorical independent variables include air conditioning usage, heating usage, fan usage, frequency of window opening and trailer manufacturer type. The emission factor, concentration and exposure were then determined. 


\section{INTRODUCTION}

The main objective of this study was to derive a web-based tool to estimate the formaldehyde exposure received by occupants of FEMA THUs.

The Federal Emergency Management Administration (FEMA) had supplied over 100,000 emergency THUs to families that lost their homes in Louisiana and Mississippi during the Hurricane Katrina and Rita disasters. FEMA owns an approximate total of 160,000 of these THUs. Some are deployed to other parts of the U.S., some are used to house emergency workers, and many are in storage. Concerns about the indoor environmental quality in the THUs have arisen based on adverse health complaints and symptoms reported by occupants. These health concerns have been identified by physicians treating THU occupants, and previous risk assessments indicate that THU occupants are at higher risk for these adverse health effects based on indoor air quality measurements made in both occupied and unoccupied THUs (Sierra Club and The Centers for Disease Control and Prevention, $\mathrm{CDC}^{5}$ ). Formaldehyde concentrations observed in both occupied and unoccupied THUs have exceeded the National Institute for Occupational Safety and Health (NIOSH) ${ }^{5}$ recommended exposure limit (REL) of 0.016 ppm, often by a factor of 10 or greater. The NIOSH REL was based on the analytical limit of detection and not on health effects data ${ }^{6}$.

Maddalena et al. ${ }^{7,8}$, measured the indoor concentration and whole trailer emission factors in four unoccupied THUs of a suite of volatile organic compounds (VOCs), including aldehydes. The study also determined the material specific emission factors of the compounds from individual surface materials collected directly from the THUs. It was observed that all THUs had a significant portion of the internal surface area constructed with $1 / 8$-inch plywood with a vinyl or PVC skin or simulated wood finish. All units had sheet vinyl flooring, while two of the four trailers also had carpeted areas. All countertops were particleboard surfaced with high-pressure laminate. A variety of wood products were used for the sub-floor and for the bench and bed platforms. Of the VOCs measured, formaldehyde was observed to be the only aldehyde emitted from these materials at rates sufficient to be of health concern. However, VOCs typically present when formaldehyde is observed are also emitted from materials. Like formaldehyde, which is a toxic air contaminant ${ }^{9}$, many of the other emitted VOCs are known to have low odor thresholds, high potency as respiratory irritants, and in some cases carcinogenicity.

Parthasarathy et al. ${ }^{2}$ also studied sixteen trailers for the purpose of analyzing the indoor VOC levels. Samples of VOCs, aldehydes and acetic acid were collected from the trailers at varying indoor conditions. Floor area normalized emission factors were also calculated for each VOC. Emission factors from materials are dependent on a range of environmental parameters such as temperature, relative humidity and boundary layer diffusion characteristics, which are influenced by air flow across the surface. This study also highlighted that variations in indoor temperature and relative humidity, ventilation rates and type of trailer manufacturer lead to significant variations in the indoor concentrations.

\section{Background}

\section{Materials emitting formaldehyde}

A background review and a discussion of emissions of formaldehyde from building materials and factors influencing formaldehyde emission rates, as well as health effects of formaldehyde 
has been presented in the companion to this report ${ }^{2}$. In order to reduce replication, the reader is referred to that report for this information.

\section{FORMALDEHYDE EXPOSURE ASSESSMENT TOOL}

\section{Datasets Used}

Meteorological data ${ }^{3}$

Hourly meteorological data for all stations in Louisiana and Mississippi were obtained from the National Oceanic and Atmospheric Administration ${ }^{3}$ for the time period of October 2005 to December 2009. A list of weather stations closest to the centroid of each zipcode was also determined. The hourly temperature and relative humidity data from the closest weather station were obtained for each zipcode. Missing data were substituted with data from the next closest weather station that had data at the time of interest, to create complete weather datasets.

\section{CDC 2009 survey ${ }^{1}$}

Between December 2007 and April 2009, CDC carried out formaldehyde sampling and administered a survey at various THUs. The data collected were shared with LBNL via personal communication. The CDC initially carried out a stratified random sampling and survey in 519 FEMA THUs between December 2007 and January 2008 5 . The dataset obtained by LBNL was an extension of that study, however non-random sampling by request was carried out after the initial study was completed. The survey questionnaire and sampling methodology used were the same as reported in CDC 2009. The THUs sampled were predominantly located in Louisiana and Mississippi. The survey was carried out in the following THU types:

- Travel trailer - Housing units with floor area less than 320 square feet. They are used as temporary housing during travel, and are regulated by state transportation authorities. Travel trailers make up a majority of the THUs deployed by FEMA.

- Park Models - Housing units with floor area about 320 - 400 square feet. Similar to travel trailers, sometimes park models are also regulated by transportation authorities. They may also voluntarily accept American National Institute Standards of construction.

- Mobile homes - Housing units with typical floor area greater than 400 square feet. These units are regulated by the U.S. Department of Housing and Urban Development (HUD).

CDC personnel collected one-hour continuous formaldehyde sampling in the THUs, along with indoor temperature and relative humidity. CDC personnel also administered a survey to the occupants of the THUs. The survey collected demographic information about the occupants of the THUs such as the number of occupants in the THU and their age. Additionally, information on the routine activities in the trailer that can contribute to formaldehyde was also gathered. The survey questioned the occupants on activities such as cooking, smoking, time spent indoors, air conditioning use, heating use, and time spent sleeping. The survey also gathered information on occupant habits that could affect the ventilation in the THUs. It included questions on occupant habits such as use of fans, leaving windows, doors or hatches open. The occupants were questioned on their use of glue, moth balls, air fresheners, closet fresheners, candles and nailpolish in the THUs. Additionally, questions on the condition of the THU roof, siding, and pipes and presence of mold, helped glean information about the current state of the THU. The data 
from this survey were used for estimating the formaldehyde concentrations in park models, mobile homes and other types of THUs. The data are also used for estimating the variability in formaldehyde emission factor across various travel trailer THU manufacturers. In this survey about $50 \%$ of the THUs sampled were mobile homes. Various statistics from this survey are presented in Tables 1-9. The survey was carried out for more than one year, hence the variations in temperature and relative humidity as the seasons change are reflected in the data. The temperature ranges from $5{ }^{\circ} \mathrm{C}$ to $37^{\circ} \mathrm{C}$, and the relative humidity vary from $16 \%$ to $90 \%$ relative humidity. The formaldehyde concentrations in travel trailer THUs were shown to be higher than in mobile homes and park models.

\section{6-THU Study ${ }^{2}$}

Parthasarathy et al. ${ }^{2}$ studied sixteen previously occupied THUs of the travel trailer type to assess emissions of volatile organic compounds including formaldehyde. The THUs selected for study were made by five manufacturers who supplied a majority of the THUs to FEMA. The whole trailer emission factors* were evaluated for 36 VOCs. Indoor sampling was carried out in the THUs located in Purvis staging yard in Purvis, Mississippi. Indoor temperature and relative humidity $(\mathrm{RH})$ were also measured in all the trailers during sampling. Indoor temperatures were increased or decreased in some of the units using the trailers' heating and air conditioning systems. The ventilation rates were also increased in some units using bathroom fans and vents. Indoor temperatures during sampling ranged from $14^{\circ} \mathrm{C}$ to $33^{\circ} \mathrm{C}$, and relative humidity $(\mathrm{RH})$ varied between $35 \%$ to $74 \%$. The ventilation rates varied from 0.14 to $4.3 \mathrm{~h}^{-1}$, as reported in Table 10. The effects of temperature, relative humidity, ventilation rates and manufacturer types on formaldehyde emission factors were studied. The data from this study was used to estimate the emission factor in travel trailer THUs as a function of temperature, $\mathrm{RH}$ and ventilation.

\section{EXPOSURE ASSESSMENT METHODOLOGY}

\section{Regression Models - Overview}

Two empirical modeling approaches were developed for assessing formaldehyde exposures in temporary housing units. The first approach was developed for the travel trailer type units and consisted of a regression analysis to estimate whole unit emission factors as a function environmental parameters and the emission factors were then used to estimate indoor formaldehyde concentrations using a mass balance approach. The second approach was developed for the other THU types and consisted of a regression analysis using survey data and co-located meteorological data to estimate indoor formaldehyde concentrations. The prediction concentration profile from both regression approaches were then used to characterize exposure based on user supplied information about occupancy. SAS 9.1 (Cary, NC) was used for all the statistical regression analysis performed in this study. The models are described below:

\section{1) Predicting Indoor Temperature and Relative Humidity in all THU types}

Linear regression models were first constructed to predict the indoor temperature and relative humidity based on the outdoor temperature and relative humidity (Figures 1,2). Indoor temperature and relative humidity along with the date and time of sampling were obtained from

*-Whole trailer emission factors are the apparent emission rates of a building or room but normalized to the floor area of the space with units of micrograms chemical per meters squared per hour and are calculated from the measured steady state concentrations assuming the only removal pathway for the chemical in the space is by fresh air ventilation. 
the CDC 2009 survey $^{1}$. Information about use of heating or air conditioning around the sampling time was obtained from the survey. Using geocoding, the latitude/longitude coordinates of the THUs sampled were obtained based on their addresses. The purpose of the latitude/longitude coordinates of the THUs were to locate the nearest weather station in the corresponding state, from which the hourly outdoor temperature and relative humidity were obtained ${ }^{3}$ for the time and date the sampling was carried out at the THU.

Estimating indoor temperature in all THU types: The parameters for a multivariate regression model for indoor temperature (from CDC 2009 survey $^{1}$ ) were optimized using outdoor temperature from the nearest weather station (from $\mathrm{NOAA}^{3}$ ) as a continuous independent variable along with air conditioning and heating use (from CDC survey ${ }^{1}$ ) data as categorical independent variables and minimizing the difference between indoor and outdoor temperature. The coefficients of outdoor temperature, air-conditioning use and heating use were all found to be significant in the model at $95 \%$ confidence $(p<0.0001)$ level as reported in Table 11 . The model was also found to yield an acceptable fit with the data with an $\mathrm{R}^{2}$ of 0.595 .

Estimating indoor relative humidity in all THU types: The same approach was used for $\mathrm{RH}$ as described for indoor temperature above. The parameters of a multivariate regression model of indoor relative humidity were optimized by minimizing the difference between predicted and measured (from CDC 2009 survey $^{1}$ ) indoor relative humidity. The parameters include coefficients for outdoor relative humidity and temperature (from $\mathrm{NOAA}^{3}$ ) as continuous independent variables along with air conditioning and heating use (from CDC survey ${ }^{1}$ ) as categorical independent variables. The coefficients of outdoor temperature and relative humidity, and air-conditioning use all found to be significant at the $95 \%$ confidence $(p<0.0001)$ level. The coefficient of heating use was found to be significant at $\mathrm{p}<0.07$ level as reported in Table 12. The model was also found to yield a good fit with the data with an $\mathrm{R}^{2}$ of 0.774 .

\section{2) Estimating Formaldehyde concentration in the Park Model, Mobile Home and Other THUs types}

Multivariate regression was performed on the CDC 2009 survey $^{1}$ data which yielded the following regression model for estimating the concentration of formaldehyde in mobile homes, park models and other THUs (Figure 3). The following significant variables or coefficients were used in the linear model: log of estimated percentage indoor relative humidity, and inverse of estimated indoor temperature (in $\mathrm{K}^{-1}$ ) were set as continuous independent variables, air conditioning usage, heating usage, fan usage, window use and trailer type as categorical independent variables. Based on the Arrhenius equation, an exponential relationship was assumed between temperature and emission factors in the regression model. Similar to previous studies $^{36}$ this study assumes a linear relationship between emission rate and relative humidity. The log of formaldehyde concentration (from CDC 2009 survey) was the dependent variable. The coefficients of inverse temperature, log relative humidity, air-conditioning, heating, window use, and fan use were found to be statistically significant at the $97.5 \%$ confidence level $(p<0.03)$, as reported in Table 13. The overall empirical model for estimating formaldehyde concentration in non-travel trailer THUs was found to yield a satisfactory fit with the data with an $\mathrm{R}^{2}$ of 0.371 . 
Upon obtaining the concentration $\left(\mu \mathrm{g} \mathrm{m}^{-3}\right)$ from the regression model the whole trailer emission rates normalized to floor area were calculated. The equation for calculating area-specific emission rates, $\mathrm{EF}_{\text {pred }}\left(\mu \mathrm{g} \mathrm{m}^{-2} \mathrm{~h}^{-1}\right)$ is

$$
E F_{\text {calc }}=\frac{f \times C_{\text {pred }}}{A}
$$

where $f\left(\mathrm{~m}^{3} \mathrm{~h}^{-1}\right)$ is the ventilation flow rate, $A\left(\mathrm{~m}^{2}\right)$ is the exposed surface area of the material or the floor area of the whole trailer, $C_{\text {pred }}\left(\mu \mathrm{g} \mathrm{m}^{-3}\right)$ is the formaldehyde concentration in the THUs predicted by the linear model. The internal volume of the trailers also comprised of inaccessible volumes occupied by furniture. Air changes per hour estimates are not readily available for the whole trailer measurements, however values for ACH were obtained from literature (Table 15)

$$
E F_{\text {calc }}=\frac{A C H \times C_{\text {pred }}}{L}
$$

To get the floor area normalized emission rate for the whole trailer experiments we note that $\mathrm{ACH}$ is equal to $\mathrm{f} / \mathrm{V}$ as indicated above and that $\mathrm{V}$ is the floor area multiplied by the height, $\mathrm{h}$ (m) so that Eq. 3 may also be written as

$$
E F_{\text {calc }}=A C H \times h \times C_{\text {pred }}
$$

Tables 15 and 16 detail the $\mathrm{ACH}, h$ and loading factors used in Equation (3). The emission factors were used to re-evaluate the steady state formaldehyde concentrations (See Section 4).

\section{3) Estimate of Formaldehyde Emission Factors in Travel Trailer THUs}

A linear regression model was constructed for whole-trailer emission factor using data from the 16-THU study ${ }^{2}$. The log of formaldehyde emission factors was the dependent variable. The log of percentage relative humidity, inverse of temperature (in $\mathrm{K}^{-1}$ ), and the log of the inverse of the air change rate $\left(\mathrm{h}^{-1}\right)$ were the independent variables (Figure 4) (these values were measured in the 16-unit study so actual values were used here to develop the empirical model). Based on the Arrhenius equation, an exponential relationship was assumed between temperature and emission factors in the regression model. A linear relationship was assumed between log of the relative humidity and $\log$ of emission factor based on previous studies ${ }^{10}$. A categorical variable was added for each different trailer manufacturer. The coefficients for inverse temperature, and log relative humidity and inverse air change rate with log emission factor were found to be statistically significant at the $95 \%$ confidence level $(\mathrm{p}<0.05)$, as reported in Table 16 . This regression model with an $\mathrm{R}^{2}$ of 0.84 was found to yield a good fit with the experimental data. The model predicts the formaldehyde emission factors from travel trailer that are used to evaluate steady state formaldehyde concentrations (See Section 4).

Estimating air change rate for travel trailer types: The 16-unit study used to develop the empirical model for the formaldehyde emission factors used measured ventilation rates and unoccupied conditions. To relate these emission factors to occupied conditions, relevant air change rates are needed. About 135 travel trailer samples of the manufacturer types studied in the Purvis trailer study were randomly selected from the CDC survey to estimate the ventilation rates. A batch input file was developed for input into the exposure assessment tool. The exposure assessment tool was run in batch mode and the concentrations in the travel trailers at 
the hour of interest were extracted from the output files. The method was used to obtain an estimate of the air change rates in the trailer during periods of occupancy. The sum of squares of the difference between measured concentration $\left(\mathrm{C}_{\text {meas }}\right)$ from the $\mathrm{CDC}$ survey and the predicted concentration $\left(\mathrm{C}_{\mathrm{pred}}\right)$ from the tool was calculated.

$$
\text { Sum of square of error }=\sum_{i}\left(C_{\text {pred }}-C_{\text {meas }}\right)_{i}^{2}
$$

Multiple runs of the tool were conducted using air change rates ranging from 0.4 to $1.5 \mathrm{~h}^{-1}$. The minimum sum of squares of the differences was obtained at an air change rate of $0.7 \mathrm{~h}^{-1}$ (Figure 5). The ACH of $0.7 \mathrm{~h}^{-1}$ was set as the constant $\mathrm{ACH}$ for travel trailer THUs in the model. Hence, the error minimization method was used to assess the ventilation rates in travel trailers under occupied conditions.

Variability across travel trailer manufacturer types: The emission factor estimation model for THUs built from the 16-THU ${ }^{2}$ dataset includes a categorical variable for five travel trailer THU manufacturer types. In order to account for environmental and THU usage variations we developed another linear regression model using the CDC survey. A linear regression model was constructed setting the log of predicted percentage indoor relative humidity, inverse of predicted indoor temperature (in $\mathrm{K}^{-1}$ ) as continuous independent variables, air conditioning usage, heating usage, fan usage, window use and trailer manufacturer type as categorical independent variables, and log of formaldehyde emission factors as the dependent variable.

The model was used to determine the ratio in emission factor variability across manufacturer types with respect to Pilgrim International THUs, by substituting similar values of temperature, relative humidity and other parameters in the model. Ratios $\left(\mathrm{THU}_{\mathrm{j}}\right.$ see Figure 4$)$ of emission factors were determined for all manufacturers whose sample size in the data exceeded $4 \%$ of the total number of samples evaluated. All other manufacturers were classified in the "Other" category.

\section{4) Estimate of Steady-State Formaldehyde Concentration in the THUs}

The THUs are assumed to be in pseudo-steady state and well mixed, which means that the neither the environmental conditions nor the emission rates are changing so that the observed or predicted concentrations also remain unchanged with time. It was assumed that the background formaldehyde concentration in outdoor air is negligible. A mass balance under these conditions yields the following differential equation (see Figure 5):

$$
\frac{d C_{i}}{d t}=S_{i}-A C H \times C_{i}
$$

where,

$$
\begin{aligned}
& \frac{d C_{i}}{d t}=\text { Rate of change of formaldehyde concentration in the THU }\left(\mu \mathrm{g} \mathrm{m}^{-3} \mathrm{~h}^{-1}\right) \\
& \mathrm{S}_{1}=\text { Formaldehyde generated in the THU }\left(\mu \mathrm{g} \mathrm{m}^{-3} \mathrm{~h}^{-1}\right)=\frac{E F}{h} \\
& \mathrm{EF}=\text { Formaldehyde emission factor predicted by linear regression models }\left(\mu \mathrm{g} \mathrm{m}^{-2} \mathrm{~h}^{-1}\right)
\end{aligned}
$$


$\mathrm{h}=$ Ceiling height of the THU (m) (see Table 16)

$\mathrm{ACH} \times \mathrm{Ci}=$ Formaldehyde removed from the THU $\left(\mu \mathrm{g} \mathrm{m}^{-3} \mathrm{~h}^{-1}\right)$

$\mathrm{ACH}=$ Air change rate in the THU (h-1) (see Table 15)

$\mathrm{C}_{\mathrm{i}}=$ Formaldehyde concentration in the THU at time $\mathrm{t}_{\mathrm{i}}\left(\mu \mathrm{g} \mathrm{m}^{-3}\right)$

Equation 4 was integrated and solved to generate the hourly steady-state formaldehyde concentrations in the THUs.

\section{5) Cumulative Formaldehyde Exposure}

The cumulative formaldehyde exposure $\left(\mu \mathrm{g} \mathrm{m}^{-3} \mathrm{~h}^{-1}\right)$ was evaluated using the following formula (see Figure 6):

$$
\text { Exposure }=\Sigma_{i} C_{i} \times t_{i}
$$

where,

$C_{i}=$ Formaldehyde concentration in the trailer over time $t_{i}\left(\mu \mathrm{g} \mathrm{m}^{-3}\right)$

$t_{i}=$ Time step over which exposure is evaluated, in this tool the $t_{i}$ 's are in time steps of 1hour (h) as limited by the meteorological data used in the assessment

The time spent by each occupant in the trailer directly affects the exposure of the individual. Hence, it is important to obtain an accurate estimate of the time each occupant spent in the trailer. Long absences such as vacations, and recurring absences such as work or school must be accounted for.

\section{FORMALDEHYDE EXPOSURE ASSESSMENT WEB TOOL ${ }^{11}$}

The online formaldehyde exposure assessment tool is a compilation of regression models developed using the methodology outlined above. The exposure assessment tool asks the user a series of questions detailed below, their inputs assist in evaluating their formaldehyde exposure. The following are a list of questions the users are required to answer. See Appendix for screen shots and additional details about the tool.

\section{1) Where did you live?}

The user must select the state and the relevant zipcode of the address of residence. The locations determine the weather station from where the outdoor temperature and relative humidity data are obtained.

\section{2) What type of trailer did you live in?}

The user selects the type of THU they lived in, options include travel trailer, park model, mobile home, and other. Selecting "Travel Trailer" will also require selection of the manufacturer.

3) When did you start living in the trailer? When did you move out of the trailer? 
These dates determine the starting and ending dates of the exposure model. Since our database contains a limited set of measured outdoor temperature and humidity data, the model is only valid between 10/1/2005 and 5/1/2009, dates outside this range will not appear.

4) Were you away from the trailer on a regular basis during your stay there, due to reasons such as work, school, etc.?

The user can enter recurring times throughout a day when an individual was not in the trailer. The user can also add multiple recurring absence schedules.

\section{5) Were you away from the trailer for extended periods of time for vacations?}

Enter non-recurring dates for which an individual was absent from the trailer.

\section{6) Did you use air conditioning regularly when you lived in the trailer?}

The user can select if air conditioning was regularly used in the trailer, and then enter the setpoint temperature that was used. This will give the model a better estimate of the indoor temperature and relative humidity during hotter periods. Additionally, the tool assumes that the indoor air temperature is close to the set-point if the outdoor temperature exceeds $85^{\circ} \mathrm{F}$.

\section{7) Did you use heating regularly when you lived in the trailer?}

The user can select if heating was regularly used in the trailer, and then enter the set-point temperature that was used. This will give the model a better estimate of the indoor temperature and relative humidity during colder periods. Additionally, the tool assumes that the indoor air temperature is close to the set point if the outdoor temperature is below $60^{\circ} \mathrm{F}$.

\section{8) Did you leave the windows open regularly when you lived in the trailer?}

The user can select if the windows in the THU were opened regularly, this is a binary input.

\section{9) Did you use a fan regularly (not in the bathroom) when you lived in the trailer?}

The user can select if the fan in the THU was used regularly, this is also a binary input.

When all the parameters have been entered run the exposure model. The results from the model consist of hourly estimates of formaldehyde concentration $\left(\mu \mathrm{g} \mathrm{m}^{-3}\right)$ and formaldehyde exposure $\left(\mu \mathrm{g} \mathrm{h} \mathrm{m}^{-3}\right)$.

Details on how to use the tool are listed in Appendix A.

\section{Travel trailer model validation using CDC survey dataset}

The input file containing 185 random travel trailer samples selected from the CDC survey was input into the exposure assessment tool. The tool was run and concentrations at the hour of interest were extracted from the output files. The modeled concentrations obtained were plotted against the measured concentrations in the CDC survey dataset. The plot yielded an $\mathrm{R}^{2}$ of -0.06 indicating a poor correlation between the measured and modeled concentration (Figure 8). Ventilation rate measurements when travel trailers were occupied are not available. Ventilation rates play a significant role in determining the emission factor and the concentration of formaldehyde in the THUs. The lack of this information has likely led to significant variation between the measured and modeled concentrations. Additionally, it is difficult to characterize 
variations between individual travel trailers irrespective of the manufacturer type. This is likely another unexplained source of variation between measured and modeled concentrations. There is also an unknown level of uncertainty in measured formaldehyde concentrations, which are used in the validation dataset.

Limited availability of data does not allow for validation of the model for mobile homes, park models and other type of THUs.

\section{Limitations of the exposure assessment tool}

As seen from Table 2 most of the THUs were likely manufactured in 2005. Formaldehyde emissions have been shown to decrease over time in newly built residences; hence it is likely that we underestimate the formaldehyde exposure of the occupants of the THUs. The influence of manufacturer type on park models and mobile homes was not addressed in the model. The ventilation rates in the model were based on values reported in literature for park models, mobile homes and other type of THUs. The ventilation rates for travel trailers were estimated using the methodology outlined in this report. Ventilation rates impact the concentration and emission factors of formaldehyde in the trailer. The lack of measured ventilation rates in the THUs under occupied conditions limits the ability to make more accurate predictions about the concentration of formaldehyde in the THUs and hence the formaldehyde exposure of the occupants. There is also significant uncertainty associated with the field-measured formaldehyde concentrations, which introduces another source of uncertainty into the validation.

\section{DISCUSSION}

This report outlines a method to evaluate formaldehyde exposure of FEMA THU occupants. Various data sources are used to build linear regression models for estimating formaldehyde emission factor in the THUs. The steady-state formaldehyde concentration and time-integrated cumulative exposure were evaluated. As seen in earlier studies ${ }^{2,12}$, temperature and relative humidity have a strong influence on the concentration of formaldehyde in all types of THUs. Travel trailer THUs are found to have higher formaldehyde concentration compared to mobile homes or park models. The exposure models can account for temporal variations in formaldehyde concentrations, during the various months. Additionally, they generate hourly exposure values because the models take into effect of diurnal variations in temperature and humidity on the formaldehyde exposure. The exposure assessment can serve as a useful tool to study the long term health impacts of formaldehyde exposure on the FEMA THU occupants.

\section{ACKNOWLEDGEMENTS}

This work was supported by interagency agreement 08FED894632 by the National Center for Environmental Health (NCEH) of the Centers for Disease Control and Prevention (CDC) and the Assistant Secretary for Energy Efficiency and Renewable Energy, Office of Building Technology, State, and Community Programs of the U.S. Department of Energy (DOE) under Contract DE-AC02-05CH11231. The authors would like to thank Jennifer Logue and Meera Sidheswaran for their reviews of this paper. 


\section{REFERENCES}

1. File 2009-4-14 Cumulative Results.xls sent to Apte, M.G. (Lawrence Berkeley National Laboratory) from Noonan, G., Center for Diseases and Control on $15^{\text {th }}$ June 2009.

2. Parthasarathy, S., Maddalena, R.; Russell, M.; Apte, M.G. Field Derived Emission Factors For Formaldehyde and Other Volatile Organic Compounds in FEMA Temporary Housing Units. LBNL report number pending.

3. Weather data: http://cdo.ncdc.noaa.gov/qcled ascii/.

4. Sierra Club. Toxic Trailers: Tests Reveal High Formaldehyde Levels in FEMA Trailers. April 2008. http://www.sierraclub.org/ (accessed October 2009).

5. Centers for Disease Control and Prevention. Final Report on Formaldehyde Levels in FEMA-Supplied Trailers, Park Models, and Mobile Homes. 2008. www.cdc.gov/nceh/ehhe/trailerstudy/ (accessed October 2009).

6. National Institute for Occupational Safety and Health. NIOSH Pocket Guide to Chemical Hazards and Other Databases. Publication Number : NIOSH 2005-149. Department of Health and Human Services. Center for Disease Control and Prevention, National Institute for Occupational Safety and Health. Cincinnati, OH, 2005.

7. Maddalena, R. Russell, M., Sullivan, D.P., Apte, M.G. Aldehyde and Other Volatile Organic Chemical Emissions in Four FEMA Temporary Housing units. Report LBNL254E. 2008.

8. Maddalena, R., Russell, M., Sullivan, D.P., Apte, M.G. Formaldehyde and Other Volatile Organic Chemical Emissions in Four FEMA Temporary Housing Units. Environmental Science and Technology. 2009,43,No.15, pp 5626-5632.

9. Agency for Toxic Substances and Disease Registry. Toxicological Profile for Formaldehyde. Public Health Service, U.S. Department of Health and Human Services, Atlanta, GA, 1999.

10. Berge, A., Mellegaard, B. Formaldehyde release from particleboard - Evaluation of a mathematical model. Holz als Roh- und Werkstoff. 1980, 38 , pp 251-255.

11. http://iep20.lbl.gov/fema/fema model.php

12. Parthasarathy, S., Maddalena, R.; Russell, M.; Apte, M.G. Effect of temperature and humidity on formaldehyde emissions in temporary housing units. Report LBNL3547E. 2010. 


\section{TABLES}

Table 1 - THU Location. Statistics from the CDC Survey ( $\mathrm{n}=3559)$.

\begin{tabular}{|c|c|c|}
\hline Where was the THU located? & Number & $\%$ \\
\hline LA & 2064 & $58.0 \%$ \\
\hline MS & 1494 & $42.0 \%$ \\
\hline
\end{tabular}

Table 2 - THU year of manufacture. Statistics from the CDC Survey $(n=3559)$.

\begin{tabular}{|c|c|c|}
\hline Year of Manufacture & Number & $\%$ \\
\hline 2001 & 1 & $0.03 \%$ \\
\hline 2003 & 4 & $0.1 \%$ \\
\hline 2004 & 162 & $4.6 \%$ \\
\hline 2005 & 2260 & $63.5 \%$ \\
\hline 2006 & 463 & $13.0 \%$ \\
\hline 2007 & 8 & $0.2 \%$ \\
\hline 2008 & 49 & $1.4 \%$ \\
\hline Unknown & 611 & $17.2 \%$ \\
\hline
\end{tabular}

Table 3 - THU Type. Statistics from the CDC Survey $(\mathrm{n}=3559)$.

\begin{tabular}{|l|c|c|}
\hline Trailer Type & Number & $\%$ \\
\hline Travel Trailer & 1283 & $36.1 \%$ \\
\hline Park Model & 412 & $11.6 \%$ \\
\hline Mobile Home & 1768 & $49.7 \%$ \\
\hline Other & 95 & 0.0267 \\
\hline
\end{tabular}

Table 4 - Window usage. Statistics from the CDC Survey $(n=3559)$.

\begin{tabular}{|l|c|c|}
\hline Do you leave windows open? & Number & $\%$ \\
\hline $1=$ Yes & 1487 & $41.8 \%$ \\
\hline $2=$ No & 1939 & $54.5 \%$ \\
\hline $3=$ Don't Know & 132 & $3.7 \%$ \\
\hline
\end{tabular}

Table 5 - Heating usage. Statistics from the CDC Survey $(\mathrm{n}=3559)$.

\begin{tabular}{|l|c|c|}
\hline Do you use heating? & Number & $\%$ \\
\hline Yes & 92 & $2.6 \%$ \\
\hline No & 3450 & $97.0 \%$ \\
\hline Don't know & 16 & $0.4 \%$ \\
\hline
\end{tabular}


Table 6 - Air conditioning usage. Statistics from the CDC Survey $(n=3559)$.

\begin{tabular}{|l|c|c|}
\hline Do you use air-conditioning? & Number & $\%$ \\
\hline Yes & 1800 & $50.6 \%$ \\
\hline No & 1744 & $49.0 \%$ \\
\hline Don't know & 14 & $0.4 \%$ \\
\hline
\end{tabular}

Table 7: Fan usage. Statistics from the CDC Survey ( $\mathrm{n}=3559)$.

\begin{tabular}{|l|c|c|}
\hline Do you use a fan (not in the bathroom)? & Number & $\%$ \\
\hline Yes & 137 & $3.9 \%$ \\
\hline No & 3396 & $95.4 \%$ \\
\hline Don't know & 25 & $0.7 \%$ \\
\hline
\end{tabular}

Table 8 - Temperature statistics. Statistics from the CDC Survey $(\mathrm{n}=3559)$.

\begin{tabular}{|l|c|}
\hline \multicolumn{1}{|c|}{ Temperature } & $\left({ }^{\circ} \mathrm{C}\right)$ \\
\hline Minimum & 5 \\
\hline Maximum & 37 \\
\hline Median & 24 \\
\hline Average & 24 \\
\hline
\end{tabular}

Table 9 - Relative humidity statistics. Statistics from the CDC Survey ( $\mathrm{n}=3559)$.

\begin{tabular}{|c|c|}
\hline Relative Humidity $(\mathrm{RH})$ & $\% \mathrm{RH}$ \\
\hline Minimum & 16 \\
\hline Maximum & 90 \\
\hline Median & 50 \\
\hline Average & 50 \\
\hline
\end{tabular}


Table 10 - Steady state concentrations from 16-THU Study in the AM (midnight-noon) and PM (noon-midnight) and floor area normalized emission factors of formaldehyde

\begin{tabular}{|c|c|c|c|c|c|c|}
\hline \multirow[b]{2}{*}{$\begin{array}{l}\text { Day/time of } \\
\text { sampling }\end{array}$} & \multirow{2}{*}{$\begin{array}{l}\text { Trailer } \\
\text { Name }\end{array}$} & \multicolumn{2}{|c|}{ Formaldehyde } & \multirow[b]{2}{*}{ Temp $\left({ }^{\circ} \mathrm{C}\right)$} & \multirow[b]{2}{*}{ RH $(\%)$} & \multirow[b]{2}{*}{$\operatorname{VR}\left(h^{-1}\right)$} \\
\hline & & $\begin{array}{l}\text { Concentration } \\
\left(\mu \mathrm{g} \mathrm{m}^{-3}\right)\end{array}$ & $\begin{array}{l}\text { Emission Factor } \\
\left(\mu \mathrm{g} \mathrm{m}^{-2} \mathrm{~h}^{-1)}\right.\end{array}$ & & & \\
\hline 5/19/09 AM & FW 1 & 44 & 30 & 17 & 74 & 0.41 \\
\hline 5/19/09 PM & FW 1 & 110 & 74 & 25 & 63 & $0.41 *$ \\
\hline 5/19/09 AM & FW 2 & 50 & 160 & 16 & 68 & 1.8 \\
\hline 5/19/09 PM & FW 2 & 160 & 510 & 27 & 55 & $1.8^{*}$ \\
\hline 5/21/09 AM & FW 3 & 64 & 17 & 22 & 69 & $0.15^{*}$ \\
\hline 5/21/09 PM & FW 3 & 100 & 26 & 27 & 67 & 0.15 \\
\hline 5/18/09 AM & FWCA 1 & 34 & 12 & 14 & 65 & $0.20^{*}$ \\
\hline 5/18/09 PM & FWCA 1 & 87 & 30 & 23 & 66 & 0.2 \\
\hline 5/20/09 AM & FWCA 2 & 13 & 30 & 19 & 61 & $1.4^{*}$ \\
\hline 5/20/09 PM & FWCA 2 & 29 & 68 & 29 & 56 & 1.4 \\
\hline 5/21/09 AM & FWCA 3 & 26 & 11 & 23 & 69 & 0.25 \\
\hline 5/21/09 PM & FWCA 3 & 35 & 15 & 27 & 67 & $0.25^{*}$ \\
\hline 5/18/09 AM & FR 1 & 97 & 350 & 14 & 66 & $2.1^{*}$ \\
\hline 5/18/09 PM & FR 1 & 250 & 900 & 23 & 65 & $2.1^{*}$ \\
\hline 5/19/09 PM & FR $1^{\mathrm{v}}$ & 180 & 660 & 25 & 51 & 2.1 \\
\hline 5/20/09 PM & FR $1^{v}$ & 200 & 1700 & 29 & 48 & 4.8 \\
\hline 5/20/09 AM & FR 2 & 360 & 170 & 19 & 61 & $0.28^{*}$ \\
\hline 5/20/09 PM & FR 2 & 1000 & 480 & 30 & 59 & 0.28 \\
\hline 5/21/09 AM & FR 3 & 79 & 40 & 22 & 72 & 0.3 \\
\hline 5/21/09 PM & FR 3 & 130 & 67 & 26 & 71 & $0.30^{*}$ \\
\hline 5/18/09 AM & GC 1 & 32 & 26 & 14 & 67 & 0.48 \\
\hline 5/18/09 PM & GC 1 & 87 & 72 & 22 & 68 & $0.48^{*}$ \\
\hline 5/19/09 PM & $\mathrm{GC} 1^{\mathrm{v}}$ & 77 & 170 & 24 & 54 & $1.3 *$ \\
\hline 5/20/09 PM & $\mathrm{GC} 1^{\mathrm{t}}$ & 52 & 110 & 23 & 54 & $1.2 *$ \\
\hline 5/21/09 PM & GC 1 & 56 & 140 & 22 & 66 & $1.4^{*}$ \\
\hline 5/18/09 AM & GC 2 & 94 & 44 & 14 & 66 & 0.27 \\
\hline 5/18/09 PM & GC 2 & 200 & 93 & 21 & 67 & $0.27 *$ \\
\hline 5/19/09 PM & GC 2 & 110 & 59 & 23 & 54 & 0.32 \\
\hline 5/20/09 PM & GC 2 & 66 & 150 & 22 & 54 & $1.4^{*}$ \\
\hline 5/21/09 AM & GC 2 & 73 & 200 & 21 & 62 & $1.6^{*}$ \\
\hline 5/18/09 AM & KS 1 & 120 & 62 & 14 & 63 & $0.3^{*}$ \\
\hline 5/18/09 PM & KS 1 & 400 & 200 & 23 & 63 & 0.3 \\
\hline 5/20/09 AM & KS 2 & 59 & 19 & 19 & 67 & $0.19^{*}$ \\
\hline 5/20/09 PM & KS 2 & 170 & 55 & 28 & 66 & 0.19 \\
\hline 5/21/09 AM & KS 3 & 150 & 48 & 22 & 72 & 0.19 \\
\hline 5/21/09 PM & KS 3 & 190 & 60 & 26 & 70 & $0.19^{*}$ \\
\hline 5/18/09 AM & PI 1 & 190 & 79 & 14 & 62 & 0.25 \\
\hline 5/18/09 AM & PI 1 & 510 & 220 & 24 & 59 & $0.25^{*}$ \\
\hline 5/19/09 PM & PI $1^{t}$ & 270 & 430 & 16 & 49 & 0.94 \\
\hline 5/20/09 PM & PI $1^{t}$ & 860 & 610 & 33 & 41 & $0.41^{*}$ \\
\hline 5/21/09 PM & PI $1 * *$ & 560 & 800 & 28 & 56 & 0.83 \\
\hline 5/19/09 AM & PI 2 & 84 & 74 & 16 & 71 & $0.51 *$ \\
\hline 5/19/09 AM & PI 2 & 250 & 220 & 27 & 59 & 0.51 \\
\hline
\end{tabular}

Notes: $\mathrm{FW}=$ Fleetwood; FWCA $=$ Fleetwood Canada; FR = Forest River; GS = Gulfstream

Cavalier; $\mathrm{KS}=$ Keystone; $\mathrm{PI}=$ Pilgrim Temp $=$ Temperature; $\mathrm{RH}=$ Relative Humidity;

$\mathrm{VR}=$ Ventilation Rate

${ }^{t}$ - Special temperature experiment was carried out during sampling.

$\checkmark$ - Special ventilation rate experiment was carried out during sampling.

*-Ventilation rate was not measured while collecting the sample. The ventilation rate was assumed to be similar in each individual trailer.

** - Three samples were collected in the kitchen, bedroom and bunk area of Pilgrim 1 on 5/21/2009. The average concentration and emission factors are reported. 
Table 11 - Indoor Temperature Prediction Model from 16-THU Study ( $\mathrm{n}=2925)$

\begin{tabular}{|l|c|c|c|c|c|}
\hline \multirow{2}{*}{} & \multirow{2}{*}{ Coefficients } & \multicolumn{2}{|c|}{$\begin{array}{c}95 \% \text { Confidence } \\
\text { limits }\end{array}$} & \multicolumn{2}{c|}{$\begin{array}{c}\text { Regression } \\
\text { statistics }\end{array}$} \\
\cline { 3 - 4 } & & Upper & Lower & $\mathrm{R}^{2}$ & $\mathrm{p}$ \\
\hline Intercept & -193 & -188 & -198 & 0.5949 & $<0.0001$ \\
\hline Outdoor Temperature $\left(\mathrm{K}^{-1}\right)$ & 0.65 & 0.65 & 0.65 & & $<0.0001$ \\
\hline AC Use & -1.45 & 2.23 & 1.77 & & $<0.0001$ \\
\hline Heating Use & 2.00 & -0.77 & -2.13 & & $<0.0001$ \\
\hline
\end{tabular}

Table 12 - Indoor Relative Humidity Prediction Model from 16-THU Study ( $\mathrm{n}=2884$ )

\begin{tabular}{|c|c|c|c|c|c|}
\hline & \multirow[t]{2}{*}{ Coefficients } & \multicolumn{2}{|c|}{$\begin{array}{c}95 \% \text { Confidence } \\
\text { limits }\end{array}$} & \multicolumn{2}{|c|}{$\begin{array}{c}\text { Regression } \\
\text { statistics }\end{array}$} \\
\hline & & Upper & Lower & $\mathrm{R}^{2}$ & $\mathrm{p}$ \\
\hline Intercept & 57.5 & 74.5 & 40.5 & \multirow[t]{5}{*}{0.7743} & $<0.0001$ \\
\hline Outdoor Temperature $\left(\mathrm{K}^{-1}\right)$ & -0.307 & -0.263 & -0.349 & & $<0.0001$ \\
\hline Outdoor Relative Humidity $\left(\mathrm{RH}^{-1}\right)$ & 0.697 & 0.675 & 0.719 & & $<0.0001$ \\
\hline AC Use & 5.59 & 6.43 & 6.43 & & $<0.0001$ \\
\hline Heating Use & 2.37 & 4.96 & -0.23 & & 7.40E-02 \\
\hline
\end{tabular}

Table 13 - Formaldehyde Concentration in Mobile Homes, Park Models and Other THUs Prediction Model $(\mathrm{n}=2115)$

\begin{tabular}{|c|c|c|c|c|c|}
\hline & \multirow[t]{2}{*}{ Coefficients } & \multicolumn{2}{|c|}{$\begin{array}{c}97.5 \% \\
\text { Confidence limits }\end{array}$} & \multicolumn{2}{|c|}{$\begin{array}{c}\text { Regression } \\
\text { statistics }\end{array}$} \\
\hline & & Upper & Lower & $\mathrm{R}^{2}$ & $\mathrm{p}$ \\
\hline Intercept & 35.0 & 31.8 & 38.3 & \multirow[t]{10}{*}{0.3708} & $<2.0 \mathrm{E}-16$ \\
\hline $\begin{array}{l}\text { Inverse Temperature } \\
\text { Coefficient }(\mathrm{K})\end{array}$ & -9650 & -10600 & -8720 & & $<2.0 \mathrm{E}-16$ \\
\hline Log RH Coefficient $\left(\log \mathrm{RH}^{-1}\right)$ & 0.393 & 0.243 & 0.543 & & $3.0 \mathrm{E}-07$ \\
\hline Mobile Homes & Reference & & & & \\
\hline Park Models & -0.352 & -2.32 & -0.145 & & $1.7 \mathrm{E}-15$ \\
\hline Other THUs & -1.24 & -0.437 & -0.266 & & 0.03 \\
\hline AC Use & 0.268 & 0.196 & 0.339 & & $3.0 \mathrm{E}-13$ \\
\hline Heating Use & 0.386 & 0.193 & 0.578 & & $9.1 \mathrm{E}-05$ \\
\hline Window Use & -0.248 & -0.717 & -0.575 & & $1.3 \mathrm{E}-08$ \\
\hline Fan Use & -0.646 & -0.333 & -0.163 & & $<2.0 \mathrm{E}-16$ \\
\hline
\end{tabular}


Table 14 - Formaldehyde Emission Factor in Travel Trailers Prediction Model ( $\mathrm{n}=43$ )

\begin{tabular}{|c|c|c|c|c|c|}
\hline & \multirow[t]{2}{*}{ Coefficients } & \multicolumn{2}{|c|}{$\begin{array}{c}97.5 \% \\
\text { Confidence limits }\end{array}$} & \multicolumn{2}{|c|}{$\begin{array}{l}\text { Regression } \\
\text { statistics }\end{array}$} \\
\hline & & Upper & Lower & $\mathrm{R}^{2}$ & $\mathrm{p}$ \\
\hline Intercept & 28.7 & 38.4 & 19.0 & \multirow{10}{*}{0.84} & $8.70 \mathrm{E}-07$ \\
\hline $\begin{array}{l}\text { Inverse Temperature Coefficient } \\
(\mathrm{K})\end{array}$ & -4050 & -780 & -7310 & & $1.70 \mathrm{E}-02$ \\
\hline Log RH Coefficient $\left(\log \mathrm{RH}^{-1}\right)$ & -2.2 & -0.4 & -4 & & $1.80 \mathrm{E}-02$ \\
\hline $\begin{array}{l}\text { Log Inverse Air Change Rate } \\
\text { Coefficient }(\log \mathrm{h})\end{array}$ & 0.68 & 0.91 & 0.46 & & $5.00 \mathrm{E}-07$ \\
\hline Pilgrim & Reference & & & & \\
\hline Fleetwood Canada & -2 & -1.4 & -2.7 & & $8.60 \mathrm{E}-08$ \\
\hline Forest River & -0.07 & 0.53 & -0.66 & & $8.20 \mathrm{E}-01$ \\
\hline Fleetwood & -1 & -0.36 & -1.6 & & $3.20 \mathrm{E}-03$ \\
\hline Gulfstream & -1 & -0.48 & -1.6 & & 5.10E-04 \\
\hline Keystone & -0.54 & 0.09 & -1.2 & & $9.00 \mathrm{E}-02$ \\
\hline
\end{tabular}

Table 15 - Air Change Rate Values Used

\begin{tabular}{|l|c|}
\hline \multicolumn{1}{|c|}{ THU TYPE } & ACH $\left(\mathrm{h}^{-1}\right)$ \\
\hline Travel Trailers $^{\mathrm{a}}$ & 0.7 \\
\hline Mobile Homes $^{\mathrm{b}}$ & 0.4 \\
\hline Park Models $^{\mathrm{b}}$ & 0.4 \\
\hline Other THUs $^{\mathrm{b}}$ & 0.4 \\
\hline
\end{tabular}

Notes:

${ }^{a}$ The values were obtained from the error minimization methodology outlined in the report.

${ }^{\mathrm{b}}$ The values were obtained from Hodgson et $\mathrm{a}^{38}$.

Table 16 - Trailer dimensions

\begin{tabular}{|l|c|c|}
\hline \multicolumn{1}{|c|}{ THU Type } & $\begin{array}{c}\text { Floor Area } \\
\left(\mathrm{ft}^{2}\right)\end{array}$ & $\begin{array}{c}\text { Ceiling Height } \\
(\mathrm{ft})\end{array}$ \\
\hline Mobile Homes $^{\mathrm{a}}$ & 800 & 6.5 \\
\hline Park Models $^{\mathrm{a}}$ & 400 & 6.5 \\
\hline Travel Trailers $^{\mathrm{b}}$ & 320 & 6.5 \\
\hline Other $^{\mathrm{a}}$ & 400 & 6.5 \\
\hline
\end{tabular}

Notes:

${ }^{a}$ The values were obtained from the CDC survey ${ }^{1}$

${ }^{\mathrm{b}}$ The values were obtained from the 16-THU study by Parthasarathy et $\mathrm{al}^{2}$. 


\section{FIGURES}

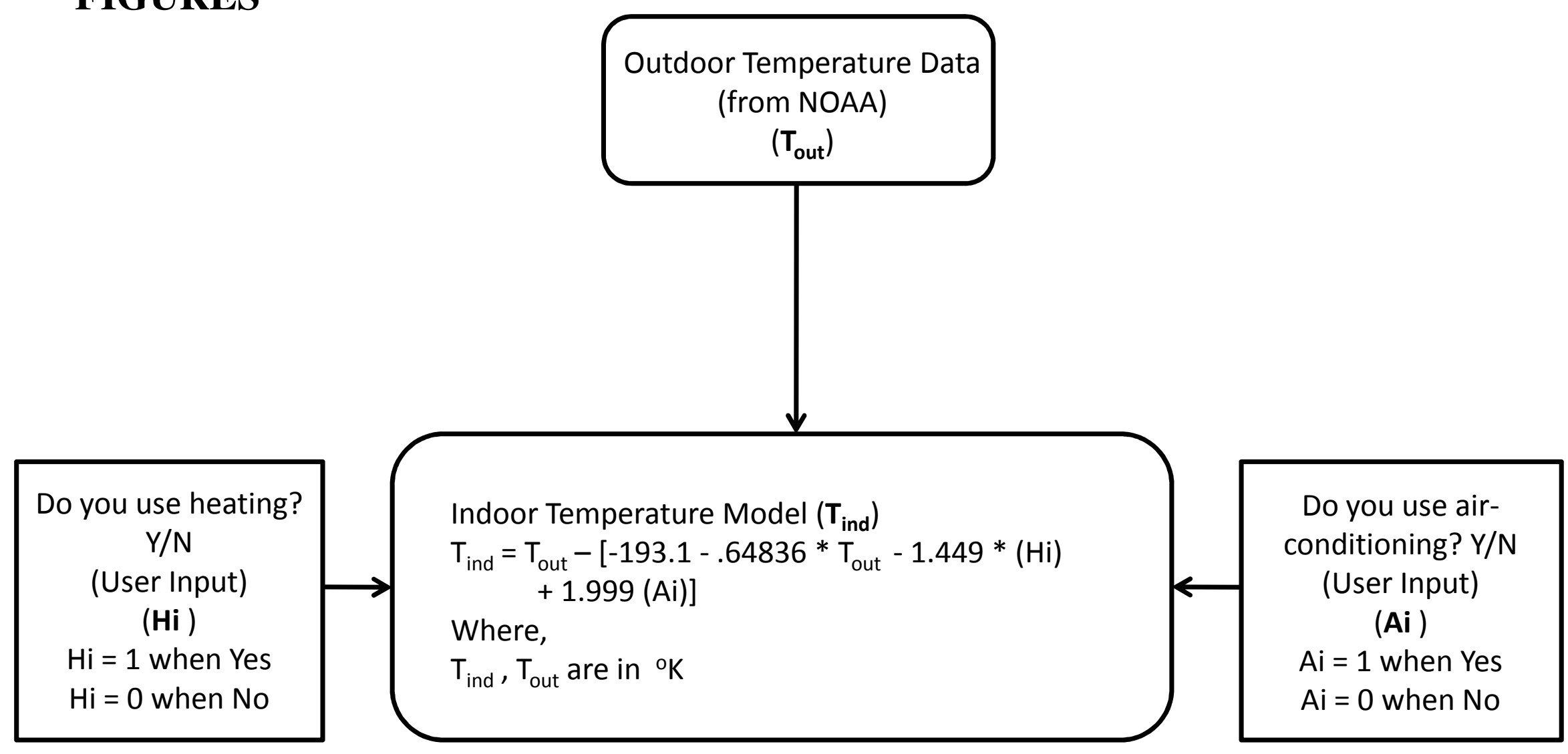

Figure 1

Model 1 : Indoor Temperature Prediction 


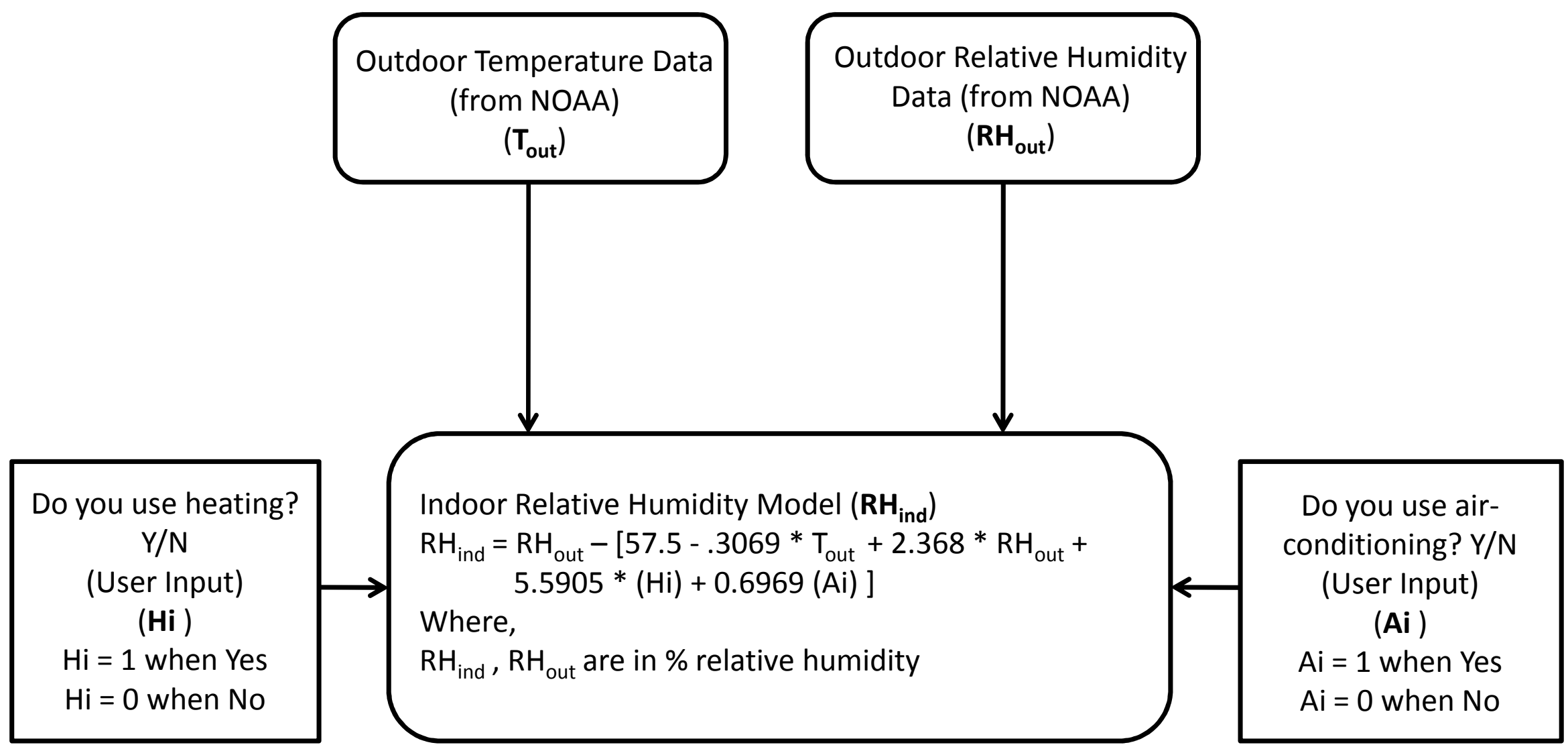

Figure 2

Model 2 : Indoor Relative Humidity Prediction 


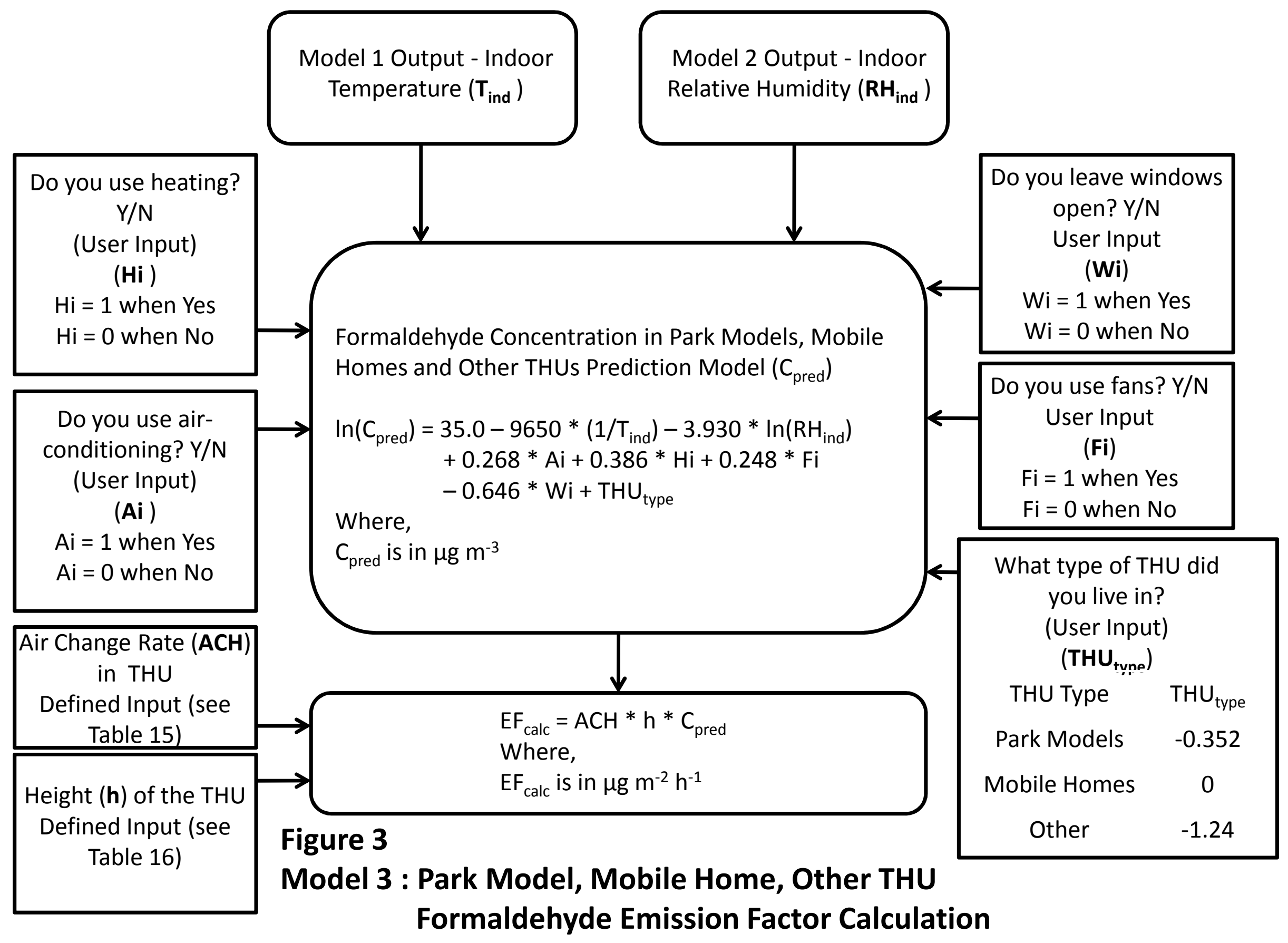




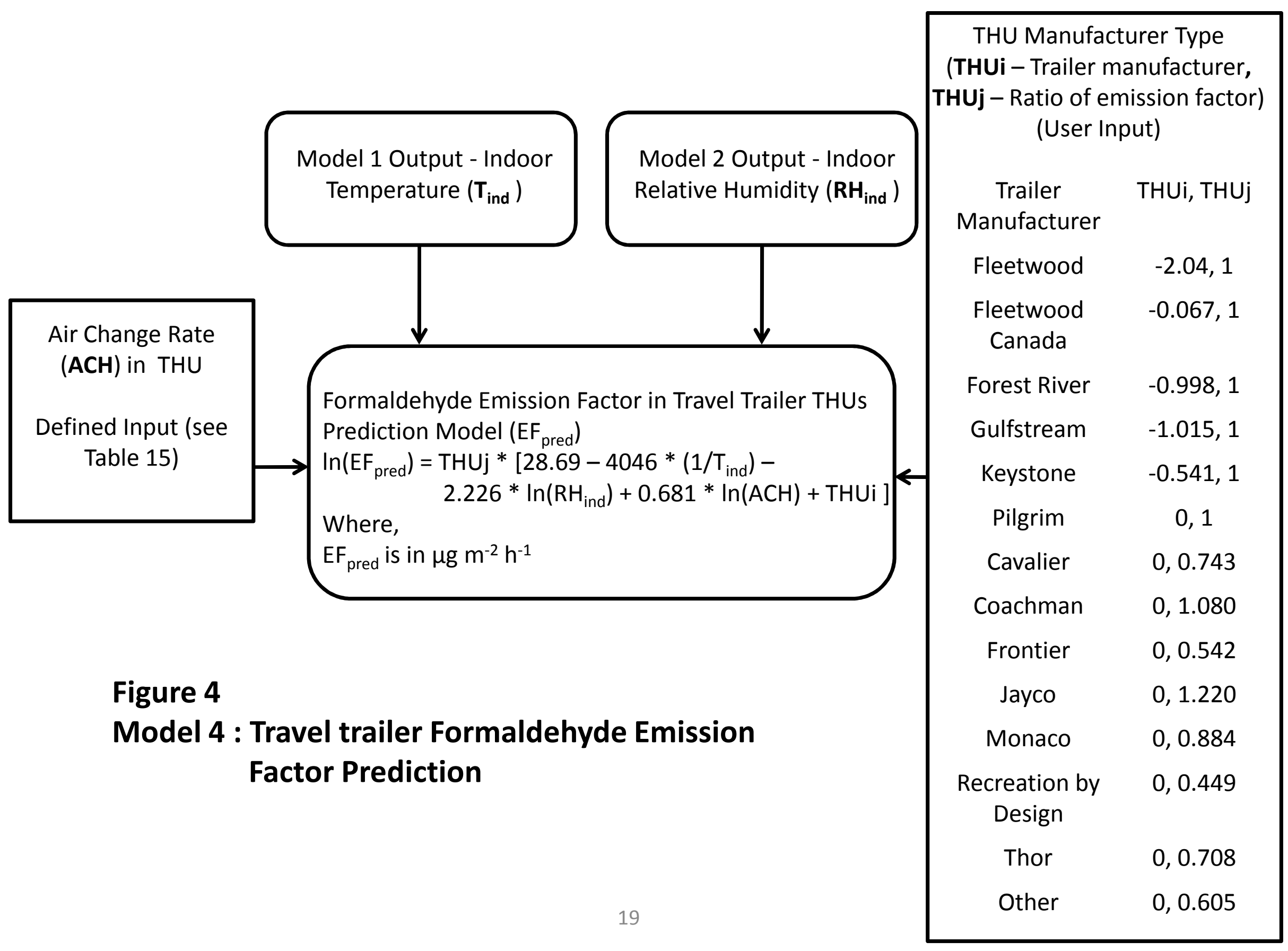


$\mathrm{C}_{0}=$ Concentration

formaldehyde in $\left(\mu \mathrm{g} \mathrm{m}^{-3}\right)$ $\mathrm{ACH}=$ Air change rate $\left(\mathrm{h}^{-1}\right)$

\section{Well mixed THU}

$C_{i}=$ Concentration formaldehyde in the THU at any time $t_{i}$ $\left(\mu \mathrm{g} \mathrm{m}^{-3}\right)$

$h=$ height of the THU (m)

Formaldehyde source with

Emission Factor EF $\left(\mu \mathrm{g} \mathrm{m}^{-2} \mathrm{~h}^{-1}\right)$
$\mathrm{C}_{\mathrm{i}}=$ Concentration

formaldehyde out $\left(\mu \mathrm{g} \mathrm{m}^{-3}\right)$

$\mathrm{ACH}=$ Air change rate $\left(\mathrm{h}^{-1}\right)$

Applying mass balance:

$$
\frac{d C_{i}}{d t}=S_{1}-A C H * C_{i}
$$

Integrating and solving the above equation yeilds $C_{i}\left(\mu g \mathrm{~m}^{-3}\right)$

\section{Figure 5}

Steady-state formaldehyde concentration in THUs 


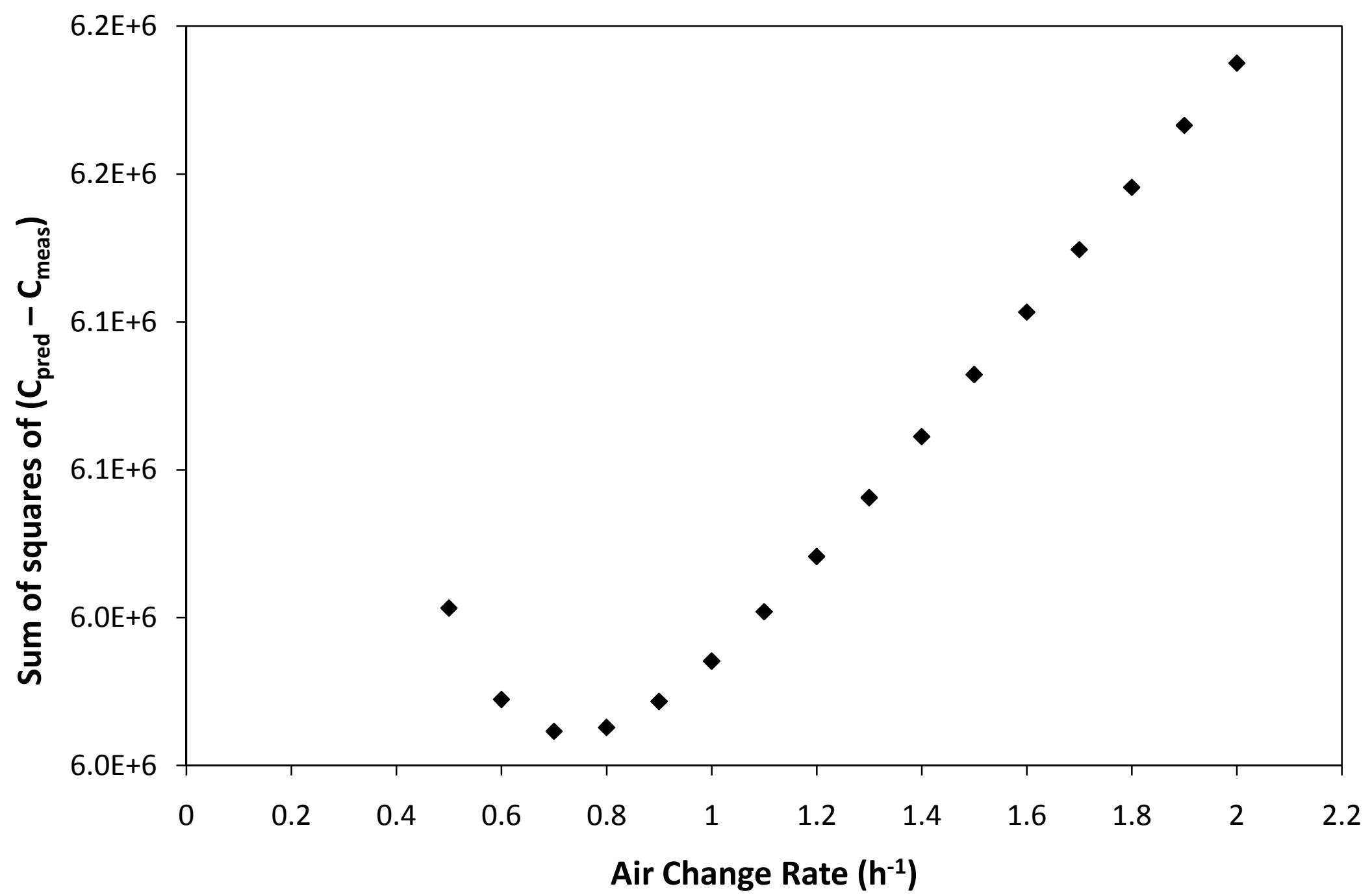

Figure 6

Error minimization methodology to estimate air change rates in travel trailer THUs 


\section{Exposure $=\Sigma_{i} C_{i} \times t_{i}$}

where,

Exposure $=$ Cumulative formaldehyde exposure over a given period of time $\left(\mu \mathrm{g} \mathrm{h} \mathrm{m}^{-3}\right)$

$C_{i}=$ Formaldehyde concentration in the trailer over time $t_{i}\left(\mu \mathrm{g} \mathrm{m}^{-3}\right)$

$t_{i}=$ Time step over which exposure is evaluated, in this tool the $t_{i}^{\prime} s$ are in time steps of 1-hour (h)

\section{Figure 7}

Exposure Assessment in the THUs 


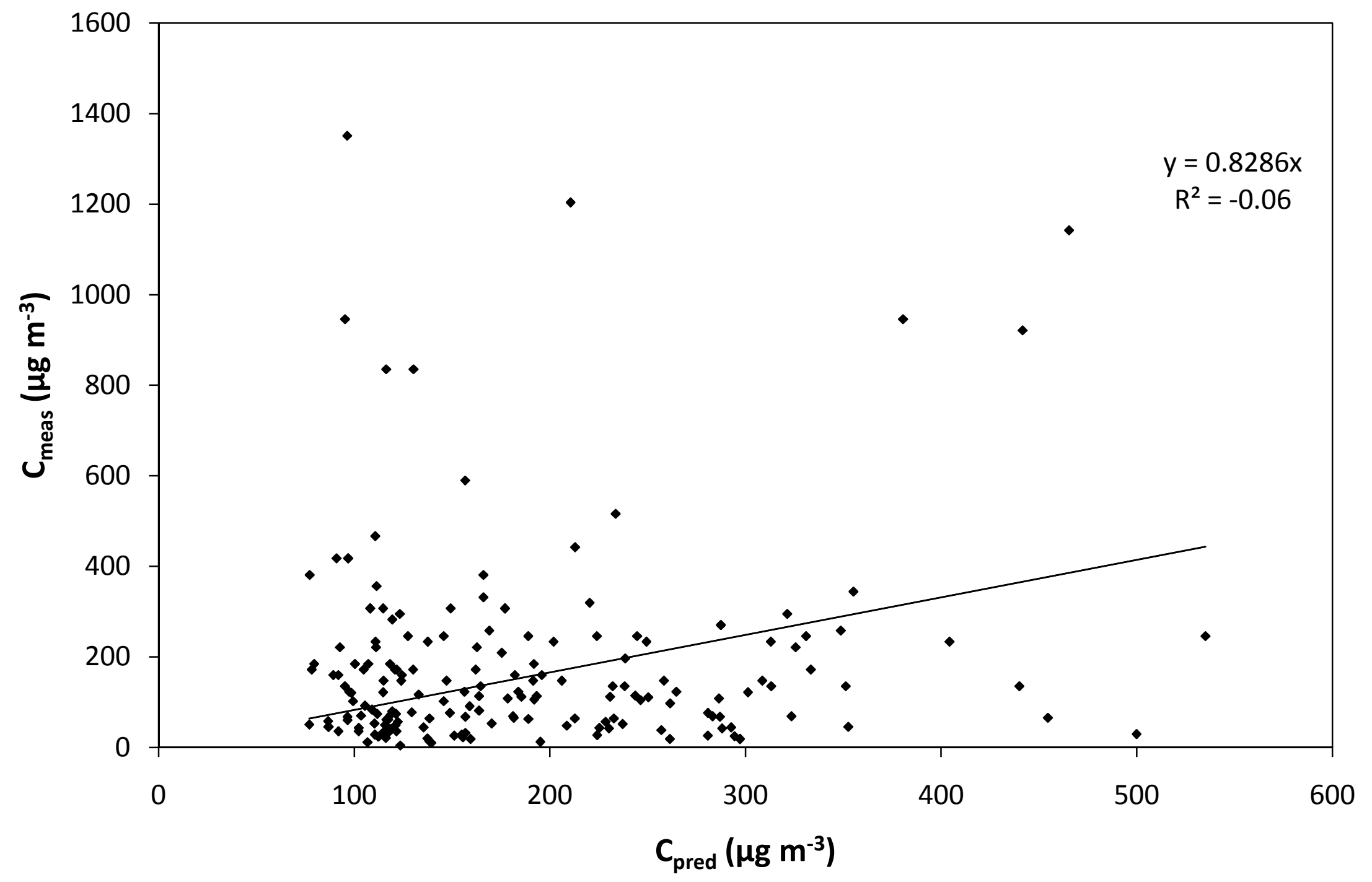

Figure 8

Model validation plot of measured concentration $\left(C_{\text {meas }}\right)$ against predicted concentration ( $C_{\text {pred }}$ ) 


\section{APPENDIX}

The web-based formaldehyde exposure assessment tool is available online at http://iep20.1bl.gov/fema/fema model.php. The guidance document was prepared to provide users information on how the tool can be used.

\section{1) Where did you live?}

Select the state and the nearest zip code where the trailer resided. If the desired zip code does not appear, select the nearest zip code to the trailer location. The exposure model will use a different set of measured outdoor temperature and relative humidity data based on the selected zip code. The model uses these outdoor values to predict indoor temperature and relative humidity.

\section{1) Where did you live? State: MS $\vee$ Zip Code: $38601 \vee$}

\section{2) What type of trailer did you live in?}

Select the type of trailer to use in the exposure model. There are three different types of trailers: travel trailer, park model, and mobile home. Selecting "Travel Trailer" will also require selection of the manufacturer (if you don't know the Travel Trailer manufacturer select "other" under "Travel trailer type").

2) What type of trailer did you live in? Park Model

\section{Choose Trailer Type}

Travel Trailer

3) When did you start living in the traile Park Model

Mobile Home

4) When did you move out of the traile Other

2) What type of trailer did you live in? Travel Trailer

2a) Select the travel trailer type: Fleetwood

\section{Fleetwood}

Fleetwood California

3) When did you start living in th Forest River Gulfstream Coach Cavalier

4) When did you move out of the Keystone

Pilgrim International

5) Were you away from the traile Other

3) When did you start living in the trailer?

4) When did you move out of the trailer?

These dates determine the starting and ending dates of the exposure model. The model is only valid between 10/1/2005 and 5/1/2009, dates outside this range will not appear. 
3) When did you start living in the trailer? January $\checkmark 2006$

4) When did you move out of the trailer? January $\checkmark 2008$,

5) Were you away from the trailer on a regular basis during your stay there, due to reasons such as work, school, etc.?

Enter recurring times throughout a day when the individual for whom the formaldehyde exposure is being calculated was not in the trailer, e.g. the individual was out of the trailer from Monday - Friday from 8:00 AM to 6:00 PM so the exposure during these times are zero. Add various times to the schedule as follows:

1. Select "Yes" on question \#5, this will show the table of dates and times for which an individual is absent from the trailer.

5) Were you away from the trailer on a regular basis during your stay there, due to reasons such as work, school, etc.? ONo $\odot$ Yes

From

To

New Date

2. Click "New Date" to enter information about when the individual was absent from the trailer.

5) Were you away from the trailer on a regular basis during your stay there, due to reasons such as work, school, etc.? $\bigcirc$ No $\odot$ Yes

Days of Week: Monday $\vee$ To Friday $v$

Times of Day: $8: 00 \vee$ To $18: 00 \vee$

Dates: January $\vee 2006 \vee$ To January $\vee 2008 \vee$

Add Date Cancel

3. Once the information has been entered click "Add Date" to add the schedule to the table, click "Cancel" to discard the operation. 
5) Were you away from the trailer on a regular basis during your stay there, due to reasons such as work, school, etc.? ONo $\odot$ Yes

From

To

Monday 8:00, 1/2006 Friday 18:00, 1/2008 remove

New Date

4. Repeat the process for multiple recurring absence schedules.

6) Were you away from the trailer for extended periods of time for vacations?

Enter non-recurring dates for which the individual for whom the formaldehyde exposure is being calculated was absent from the trailer, e.g. the individual went on vacation away from the trailer from 6/9/2007 to 6/30/2007, so exposure during these times is zero. Procedure for adding dates to the schedule is identical to question 5 .

6) Were you away from the trailer for extended periods of time for vacations? ONo $\odot$ Yes

\section{From}

To

New Date

6) Were you away from the trailer for extended periods of time for vacations? ONo $\odot$ Yes

Start of vacation: $06 / 09 / 2007$

End of vacation: $\quad 06 / 30 / 2007$

Add Date Cancel 
6) Were you away from the trailer for extended periods of time for vacations? ONo $\odot$ Yes

\begin{tabular}{|c|c|c|}
\hline \multicolumn{3}{|c|}{ To } \\
\hline $06 / 09 / 2007$ & $06 / 30 / 2007$ & remove \\
\hline
\end{tabular}

New Date

7) Did you air conditioning regularly when you lived in the trailer?

Click "Yes" if air conditioning was regularly used in the trailer, and then enter the set-point temperature that was used. This will give the model a better estimate of the indoor temperature and relative humidity during hotter periods.

7) Did you use air conditioning regularly when you lived in the trailer? ONo $\odot$ Yes What was the air conditioning set-point temperature? 78

8) Did you use heating regularly when you lived in the trailer? Click "Yes" if heating was regularly used in the trailer, and then enter the set-point temperature that was used. This will give the model a better estimate of the indoor temperature and relative humidity during colder periods.

8) Did you use heating regularly when you lived in the trailer? ONo $\odot$ Yes

What was the heating set-point temperature? $72 \quad{ }^{\circ} \mathrm{F}$

9) Did you leave the windows open regularly when you lived in the trailer?

Click "Yes" if the windows were open regularly when the trailer was occupied.

9) Did you leave the windows open regularly when you lived in the trailer? ONo $\odot$ Yes

10) Did you use a fan regularly (not in the bathroom) when you lived in the trailer? Click "Yes" if a fan was used regularly when the trailer was occupied.

10) Did you use a fan regularly (not in the bathroom) when you lived in the trailer? ONo (O) Yes

\section{Running the Model}

When all the parameters have been entered click "Run Model" to begin the exposure model, this will bring up a new browser window displaying the results. The results from the model consist 
of hourly estimates of formaldehyde concentration $\left(\mu \mathrm{g} / \mathrm{m}^{3}\right)$ and formaldehyde exposure $\left(\mu \mathrm{g} * \mathrm{~h} / \mathrm{m}^{3}\right.$ ). These values are plotted on the screen (see Formaldehyde Concentration and Formaldehyde Exposure plots below) and are also available in text form as tab-delimited files by clicking on the links "Output Concentration file" and "Output Exposure file" at the top of the page. The plots will show the entire output data set by default. Enter starting and ending dates into the "Date Range" boxes to plot specific periods of time.
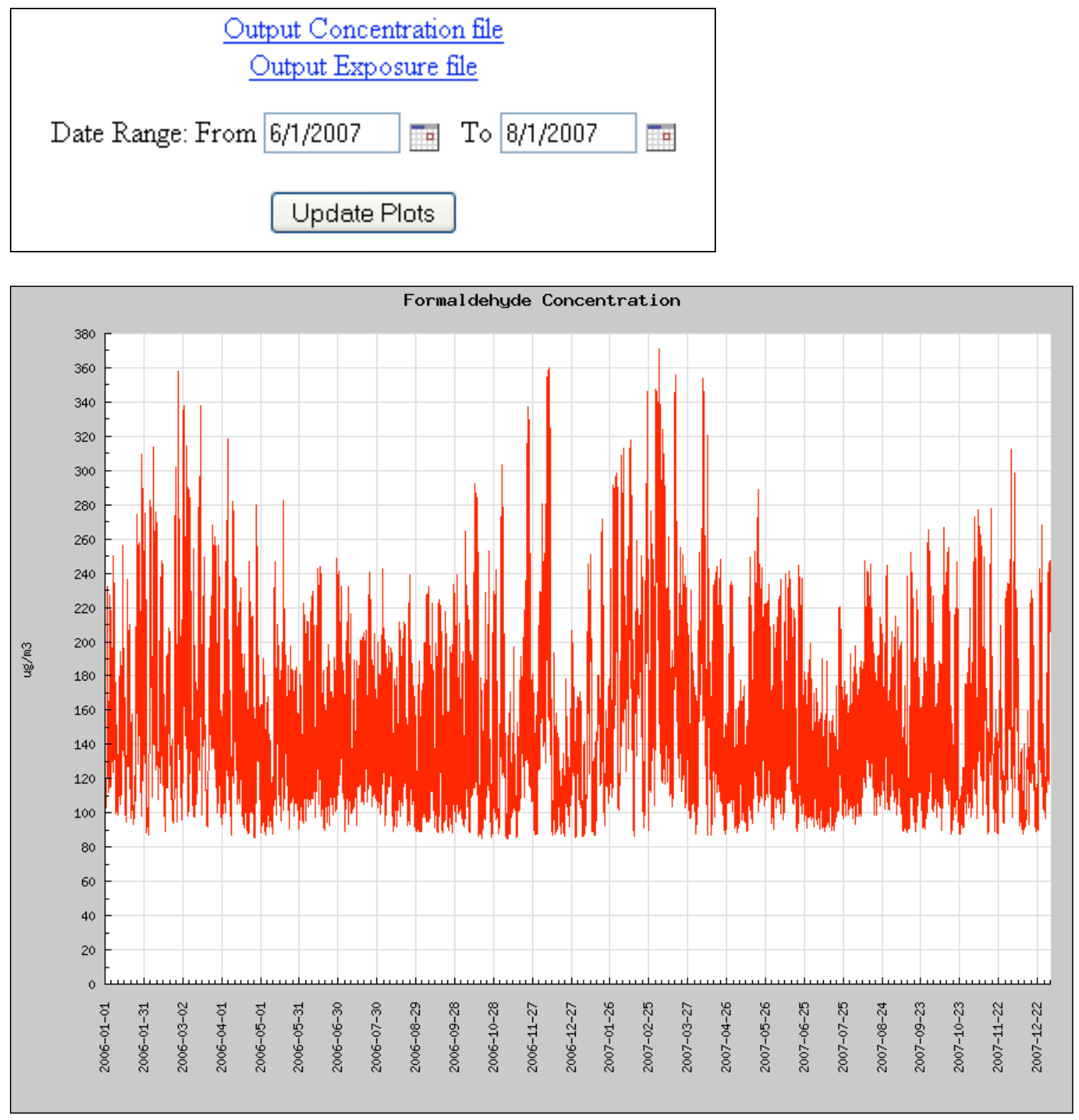


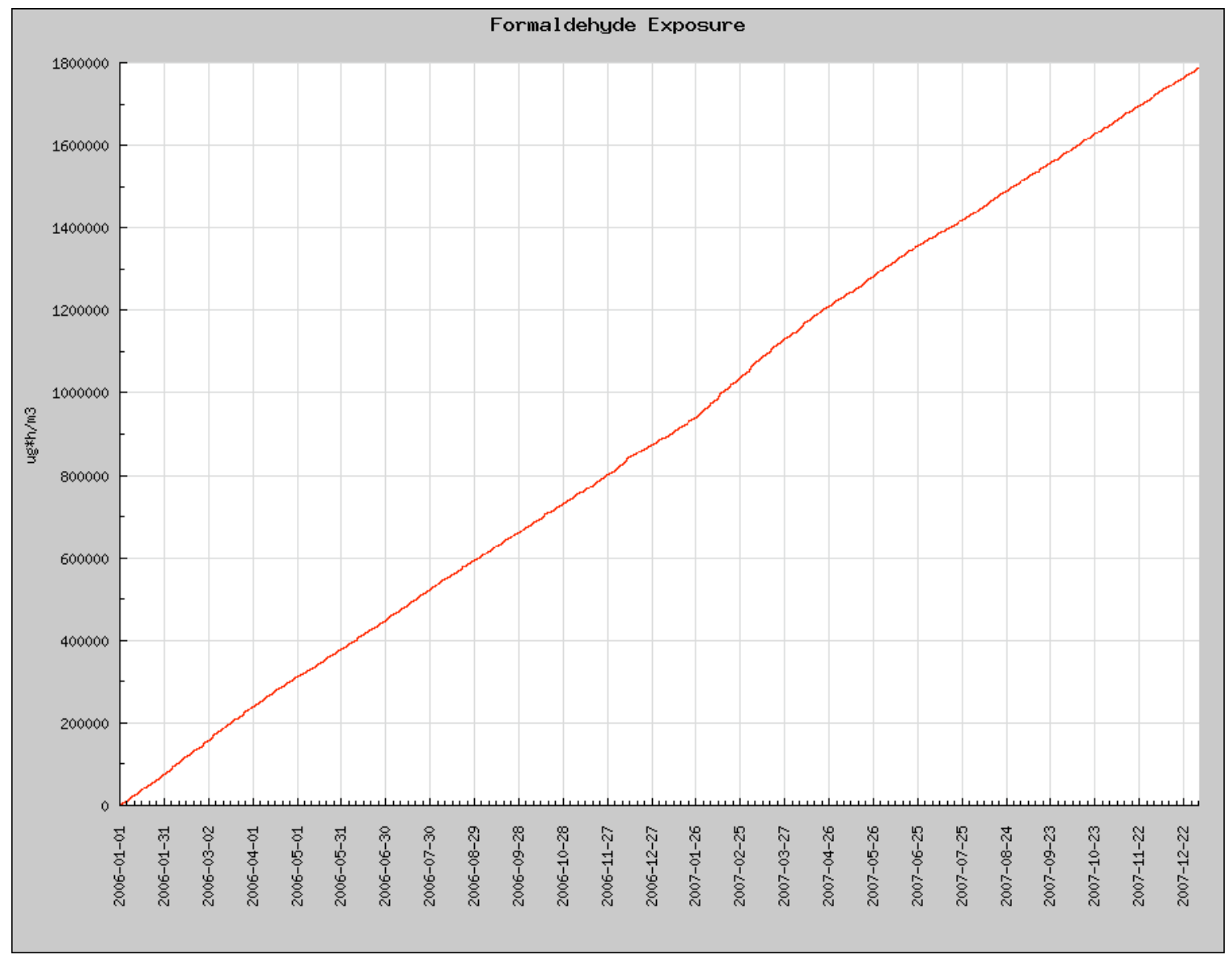

\section{Batch Mode}

The formaldehyde exposure model can be setup to run a list of different configurations to be executed at the same time. To setup a list of models to execute, define the various inputs as described above, and then click the "Add to Batch" button at the bottom of the page to add the current configuration to the list, the model definition should appear in the table at the bottom of the page. Add other model definitions in a similar manner. The model list may be saved to a text file by clicking the "Export Batch List" button.

A list of model definitions may also be imported from a text file. The web tool expects the input file to follow the following format:

- Each line contains a single model definition with commas separating the different options

- The options should appear in following order:

1. State

2. Zip code

3. Trailer type
○ Enter " $t \mathrm{t}$ " for travel trailer
○ Enter "pm" for park model
○ Enter "mh" for mobile home
- Enter "ot" for other trailer types that are not in the list

4. Manufacturer (only valid for "Travel Trailer" trailer type, leave blank otherwise

○ Enter "fw" for Fleetwood

○ Enter "fc" for Fleetwood California 
○ Enter "fr" for Forest River

○ Enter "gc" for Gulfstream Coach Cavalier

○ Enter "ks" for Keystone

○ Enter "pl" for Pilgrim International

○ Enter "ch" for Cavalier

○ Enter "cm" for Coachmen

○ Enter "ft" for Frontier

○ Enter "jc" for Jayco

○ Enter "mc" for Monaco

○ Enter "rd" for Recreation by Design

○ Enter "ti" for Thor Industries

- Enter " 0 " for other manufacturers not in the list

5. Begin Date (mm/yyyy)

6. End Date (mm/yyyy)

7. Recurring absence - Each schedule should be separated by a semi-colon (;). The inputs for each schedule should be separated by a dash (-) and should appear in the following order:

$\circ$ Beginning day of week (Sun. $=0$, Mon. $=1, \ldots$, Sun. $=6)$

$\circ$ Ending day of week (Sun. $=0$, Mon. $=1, \ldots$, Sun. $=6$ )

- Beginning hour of the day $(0-23)$

- Ending hour of the day $(0-23)$

$\circ$ Beginning date schedule is valid ( $\mathrm{mm} / \mathrm{yyyy})$

$\circ$ End date schedule is valid ( $\mathrm{mm} / \mathrm{yyyy}$ )

$\circ$ e.g. to define the two different recurring absence schedules 1) Monday - Friday from 8:00 AM - 6:00 PM from 2/06 - 2/07 and 2) Tuesday Thursday from 8:00 PM - 11:00 PM from 8/06 - 1/07, the schedule would appear as follows:

"1-5-8-18-2/2006-2/2007;2-4-20-23-8/2006-1/2007"

8. Single absence - Each schedule should be separated by a semi-colon (;). The inputs for each schedule should be separated by a dash (-) and should appear in the following order:

$\circ$ Beginning date $(\mathrm{mm} / \mathrm{dd} / \mathrm{yyyy})$

$\circ$ Ending date $(\mathrm{mm} / \mathrm{dd} / \mathrm{yyyy})$

$\circ$ e.g. if an individual was absent from the trailer from 6/9/2006 $6 / 30 / 2006$ and $12 / 20 / 2006-12 / 30 / 2006$, the schedule would appear as follows: "6/9/2006-6/30/2006;12/20/2006-12/30/2006"

9. Air conditioning set point, leave blank if air conditioning was not used.

10. Heating set point, leave blank if heating was not used.

11. Windows open - " 1 " if the windows were open regularly, " 0 " if the windows were not open regularly.

12. Fan - " 1 " if a fan was regularly used in the trailer, " 0 " if a fan was not regularly used in the trailer.

A batch input file is shown below: 
State,Zip,Trailer Type,Manufacturer,Begin Date,End Date,Work Schedule,Vacation

Schedule,AC,Heat,Windows,Fan

LA, 70118,tt,o,04/2008,04/2008, ,, ,, 0,0

MS,39573,tt,pl,06/2008,06/2008,,,75,,0,0

LA $, 70122, \mathrm{tt}, \mathrm{o}, 04 / 2008,04 / 2008,,, 75,, 0,0$

\section{Running the tool in batch mode}

1. After the input file is prepared, click on "Load Batch List" in the tool.

2. Select the physical location of the input file for upload. The tool will automatically display the information in the input file, verify that the input is read correctly.

3. Click on "Run Batch" to run the model.

4. When the model run is complete the tool will generate an*.zip file with the output formaldehyde concentrations and exposures. 